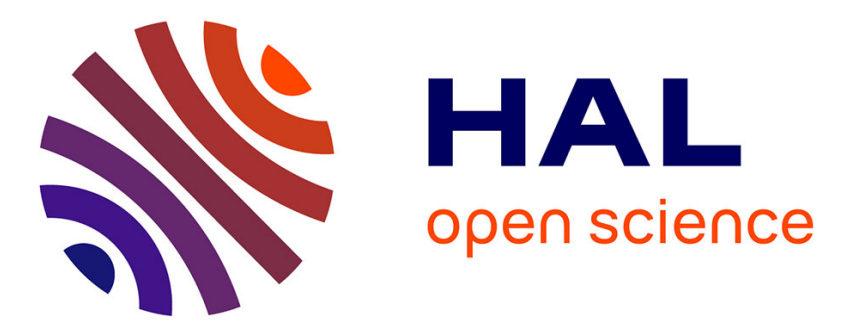

\title{
Photocatalytic Degradation of Oxytetracycline in Aqueous Solutions with TiO2 in Suspension and Prediction by Artificial Neural Networks
}

\author{
Messaoud Bennemla, Malika Chabani, Abdeltif Amrane
}

\section{- To cite this version:}

Messaoud Bennemla, Malika Chabani, Abdeltif Amrane. Photocatalytic Degradation of Oxytetracycline in Aqueous Solutions with $\mathrm{TiO} 2$ in Suspension and Prediction by Artificial Neural Networks. International Journal of Chemical Kinetics, 2016, 48 (8), pp.464-473. 10.1002/kin.21005 . hal01367226

HAL Id: hal-01367226

https://hal-univ-rennes1.archives-ouvertes.fr/hal-01367226

Submitted on 10 Oct 2016

HAL is a multi-disciplinary open access archive for the deposit and dissemination of scientific research documents, whether they are published or not. The documents may come from teaching and research institutions in France or abroad, or from public or private research centers.
L'archive ouverte pluridisciplinaire HAL, est destinée au dépôt et à la diffusion de documents scientifiques de niveau recherche, publiés ou non, émanant des établissements d'enseignement et de recherche français ou étrangers, des laboratoires publics ou privés. 
Photocatalytic degradation of Oxytetracycline in aqueous solutions with $\mathrm{TiO}_{2}$ in suspension and prediction by artificial neural networks

Messaoud Bennemla ${ }^{\mathrm{a}}$, Malika Chabani ${ }^{\mathrm{a}}$, Abdeltif Amrane $\mathrm{e}^{\mathrm{b}, \mathrm{c}^{*}}$

aaFaculté de Génie des Procédés et Génie Mécanique, U.S.T.H.B. BP 32, El Allia, Bab ezzouar, Algiers, Algeria.

${ }^{\text {b} E c o l e ~ N a t i o n a l e ~ S u p e ́ r i e u r e ~ d e ~ C h i m i e ~ d e ~ R e n n e s, ~ C N R S, ~ U M R ~ 6226, ~} 11$ allée de Beaulieu, CS 50837, 35708 Rennes Cedex 7, France

'Université Européenne de Bretagne, 5 boulevard Laënnec, 35000, France

* Corresponding author. Tel: +3322323 57 55; fax: +33223238120.

E-mail address: abdeltif.amrane@univ-rennes1.fr (A. Amrane). 


\begin{abstract}
In this study, the photocatalytic degradation of oxytetracycline (OTC) in aqueous solutions has been studied under different conditions such as initial pollutant concentrations, amount of catalyst and $\mathrm{pH}$ of the solution. Experimental results showed that photocatalysis was clearly the predominant process in the pollutant degradation, since OTC adsorption on the catalyst and photolysis are negligible. The optimal $\mathrm{TiO}_{2}$ concentration for OTC degradation was found to be $1.0 \mathrm{~g} / \mathrm{L}$. The apparent rate constant decreased and the initial degradation rate increased with increasing initial OTC concentration with the other parameters kept unchanged. Subsequently, Data obtained from photocatalytic degradation were used for training the artificial neural networks. Levenberg-Marquardt algorithm, log sigmoid function in the hidden layer and the linear activation function in the output layer were used. The optimized ANN structure was four neurons at the input layer, eighteen neurons at the hidden layer and one neuron at the output layer. The application of 18 hidden neurons allowed to obtain the best values for $\mathrm{R}^{2}$ and the mean squared error (MSE); 0.99751 and 7.504e-04, respectively; showing the relevance of the training and hence the network can be used for final prediction of photocatalytic degradation of OTC with suspended $\mathrm{TiO}_{2}$.
\end{abstract}

Keywords: Artificial Neural Networks, Photocatalytic degradation, Titanium dioxide, Antibiotics, Oxytetracycline.

\title{
1. Introduction
}

The use of medicine drugs have led to the release of various substances in the environment. The presence and accumulation of these substances in natural waters leads to the disruption of ecosystems and increases malfunction in the reproduction of aquatic species [1,2]. Among these pollutants, antibiotics deserve particular attention because they are used in very large quantities and are biologically active molecules. Therefore, great attention has been given in 
recent year to remove antibiotics from wastewaters [3-5]. Oxytetracycline was chosen in this work as a representative of this class of contaminant because it is one of the most frequently antibiotics prescribed in humans and veterinary medicine [6,7]. Hence it is important to develop efficient treatment methodologies to limit the presence of pharmaceutical contaminants in aquatic environments. Among all the possible techniques of treatment of the contaminated aqueous effluents, advanced oxidation processes of (AOPs) appear as process of choice because they lead to a total degradation of the pollutant and the reduction of effluent toxicity $[8,9]$. From all the available AOPs, heterogeneous photocatalysis using $\mathrm{TiO}_{2}$ appears as one of the most destructive technologies [10-12]. In general, $\mathrm{TiO}_{2}$ is photoactive under UV light less than $400 \mathrm{~nm}[13,14]$. Under this condition, $\mathrm{TiO}_{2}$ generates electron-hole pairs $\left(\mathrm{e}_{\mathrm{CB}}-\right.$ $\left.\mathrm{h}_{\mathrm{VB}}{ }^{+}\right)$, namely electron from conduction band $\left(\mathrm{e}_{\mathrm{CB}}{ }^{-}\right)$and hole at valence band $\left(\mathrm{h}_{\mathrm{VB}}{ }^{+}\right)(\mathrm{Eq} .(1))$, which subsequently react with $\mathrm{H}_{2} \mathrm{O}$ or $\mathrm{O}_{2}$ to generate the reactive radicals, $\mathrm{H}_{2} \mathrm{O}^{\bullet}, \mathrm{O}_{2}{ }^{\bullet-}$ and $\bullet \mathrm{OH}$, responsible of the destruction of pollutants [15,16] (Eqs.(2), (3)). Oxygen acts primarily as an efficient electron trap (Eq.(4)), preventing recombination of electrons and photogenerated holes. In acidic solution the radical superoxide ions $\left(\mathrm{O}_{2}^{\bullet-}\right)$ reacts with $\mathrm{H}^{+}$to form hydroperoxyl radical $\mathrm{HO}_{2}^{\bullet}$ as in reaction (5). If oxygen is limited, rapid recombination of photoproduced electrons and holes in $\mathrm{TiO}_{2}$ reduces significantly the efficiency of photocatalytic reactions.

Treatment of effluents by advanced oxidation processes is influenced by many parameters. Owing to the complexity of the process, they are hard to be modeled using conventional mathematical modeling. Artificial neural network (ANN), which mimics biological neural processing [17], is applied in many fields of engineering and science as a promising tool because of its simplicity in simulation and prediction [18]. Recently, some studies using artificial neural networks in modeling heterogeneous photocatalysis have been published, providing an alternative approach to the usual modelization [19-24]. 
In this study, an artificial neural network model was therefore developed in order to predict the degradation efficiency of OTC in aqueous solution under visible light irradiation. The ANN was trained using the experimental data obtained by advanced oxidation process $\left(\mathrm{UV} / \mathrm{TiO}_{2}\right)$ by varying different parameters such as time of UV irradiation, initial concentration of OTC, catalyst dose and $\mathrm{pH}$ of the solution. Multiple algorithms and transfer functions for the hidden layer were widely tested to find adequate model and reliable network architecture. The success of the model was determined by comparing the removal efficiencies of OTC obtained experimentally with those obtained from the developed program.

The $\mathrm{UV} / \mathrm{TiO}_{2}$ system can be summarized as follows [9]:

$$
\begin{aligned}
& \mathrm{TiO}_{2} \stackrel{h v}{\longrightarrow} \mathrm{TiO}_{2}+\left(e_{C B}^{-}+h_{B V}^{+}\right) \\
& h_{B V}^{+}+\mathrm{OH}^{-} \longrightarrow \mathrm{OH}^{\bullet} \\
& h_{B V}^{+}+\mathrm{H}_{2} \mathrm{O} \longrightarrow \mathrm{OH}^{\bullet}+H^{+} \\
& \mathrm{O}_{2}+e_{B C}^{-} \longrightarrow \mathrm{O}_{2}^{\bullet-} \\
& \mathrm{O}_{2}^{\bullet-}+\mathrm{H}^{+} \longrightarrow \mathrm{HO}_{2}^{\bullet}
\end{aligned}
$$

\section{Materials and methods}

\subsection{Reagents}

Oxytetracycline (OTC) was supplied by the pharmaceutical Saidal group (Algeria), with a purity higher than $99 \%$. The structure, molecular weight and maximum light absorption wavelength of OTC were $\mathrm{C}_{22} \mathrm{H}_{25} \mathrm{ClN}_{2} \mathrm{O}_{9}, 496.9 \mathrm{~g}$ and $355 \mathrm{~nm}$, respectively. OTC has a very complex chemistry, as seen in Fig. 1, with four ionic forms represented by $\mathrm{H}_{3} \mathrm{OTC}^{+}, \mathrm{H}_{2} \mathrm{OTC}$, $\mathrm{HOTC}^{-}, \mathrm{OTC}^{2-}$ and three ionization equilibriums with pKa values of 3.2, 7.5 and 8.9 [25]. The stock solution was prepared at a concentration of $1000 \mathrm{mg} / \mathrm{L}$ by dissolving OTC in bidistilled water and further diluted to the concentrations of the working solution $(5-20 \mathrm{mg} / \mathrm{L})$. The initial $\mathrm{pH}$ was adjusted to the required value by adding dilute solution $(0.1 \mathrm{~mol} / \mathrm{L})$ of $\mathrm{HCl}$ 
and $\mathrm{NaOH}$ supplied by Merck. $\mathrm{TiO}_{2}$ (Degussa $\mathrm{P} 25$, BioChem) was employed as a photocatalyst, with an average particle size of $20 \mathrm{~nm}$, a BET specific surface area close to 50 $\mathrm{m}^{2} / \mathrm{g}$, and a crystallographic mode of $70 \%$ anatase and $30 \%$ rutile.

\subsection{Photocatalytic procedure}

Experiments were conducted in a Pyrex reactor with a double walled cooling-water jacket to maintain the temperature constant and equal to $22.0{ }^{\circ} \mathrm{C}\left( \pm 2.0^{\circ} \mathrm{C}\right)$. A mercury lamp (PLL24W/10/4P,$\lambda_{\max }=365 \mathrm{~nm}$, Philips, Poland) was positioned in axial position inside the glass tube, which provide a maximum radiation at $365 \mathrm{~nm}$. The lamp and quartz tube were immersed in the axial center of the reactor. The space between the surface of the reaction solution and the light source was $1.0 \mathrm{~cm}$. The reactor was charged with $0.8 \mathrm{~L}$ of an aqueous solution containing the OTC at concentration in the range 5 to $20 \mathrm{mg} / \mathrm{L}$, to which Degussa $\mathrm{TiO}_{2}$ particles in the range $0.125-12.0 \mathrm{~g} / \mathrm{L}$ were added. Suspended solution was maintained uniform by agitation at $400 \mathrm{rpm}$ with a magnetic stirrer. The solution was stirred in dark conditions for 30 minutes to allow adsorption equilibrium to be achieved (the absorbance at this time was taken as the initial absorbance), followed by irradiation with UV light. Samples of $3 \mathrm{ml}$ were taken at regular times during 3 hours to assess the degradation performance of OTC. Prior to analysis, the aliquots were filtered through $0.2 \mu \mathrm{m}$ Millipore filters in order to separate the grains of $\mathrm{TiO}_{2}$ from the solution. The concentration of OTC in samples was

determined by measuring the absorbance with UV-visible spectrophotometer (SpectroScan 60DV coupled with the software of acquisition UV WINLAB) at $355 \mathrm{~nm}$ wavelength using a 1 cm quartz cell.

\subsection{Definition of the artificial neural network (ANN)}

In the present study, a three layer ANN with a log sigmoid transfer function 'logsig' at hidden layer and a linear transfer function 'purelin' at output layer were used (Fig. 2). LevenbergMarquardt backpropagation 'trainlm' with 1200 iterations was selected for training the 
designed networks. The parameters such as initial concentration of OTC (mg L $\left.{ }^{-1}\right)$, catalyst load (0.125- $2 \mathrm{~g})$, time of UV irradiation (min) and initial $\mathrm{pH}$ of the experimental solution are the four nodes in input layer of the network and the output layer consists of only one node, percentage degradation of OTC. The number of experimental data used in the ANN is 1792, obtained by varying four reaction parameters. The Ranges of operating variables were four initial OTC concentrations, four $\mathrm{pH}$ values, seven catalyst amounts and sixteen contact time points. The data sets were randomly divided into three groups ( $70 \%$ for the training, $15 \%$ for the testing and $15 \%$ for the validation set).

The sigmoid transfer function, which was used in this study, is given by the following equation:

$$
f(x)=\frac{1}{1+e^{-x}}
$$

This function is widely used in back propagation networks, because it is nonlinear and differentiable. The sigmoid transfer function receives the amount of input between plus and minus infinity and produces an output between zero and one based on the following formula $[26,27]:$

$y=\frac{\left(x_{i}-x_{\min }\right)}{\left(x_{\max }-x_{\min }\right)}$

where $\mathrm{y}$ is the normalized value of $\mathrm{x}_{\mathrm{i}} ; \mathrm{x}_{\max }$ and $\mathrm{x}_{\min }$ are the maximum and minimum value of $\mathrm{X}_{\mathrm{i}}$, respectively.

The Levenberg-Marquardt algorithm was designed to approach second-order training speed without having to compute the Hessian matrix. When the performance function has the form of a sum of squares, then the Hessian matrix can be approximated as follows:

$H=J^{T} J$

and the gradient can be computed as follows:

$g=J^{T} e$ 
where $J$ is the Jacobian matrix that contains first derivatives of the network errors with respect to the weights and biases, and $e$ is a vector of network errors. The Jacobian matrix can be computed through a standard back propagation technique that is much less complex than computing the Hessian matrix.

The performance of the ANN model, obtained according to the mean squared error (MSE) and the coefficient of determination $\left(\mathrm{R}^{2}\right)$ can be defined as follows:

$$
\begin{gathered}
M S E=\frac{\sum_{i=1}^{N}\left(\left|y_{p, i}-y_{\text {exp }, i}\right|\right)^{2}}{N} \\
R^{2}=1-\frac{\sum_{i=1}^{N}\left(y_{p, i}-y_{\text {exp }, i}\right)}{\sum_{i=1}^{N}\left(y_{p, i}-y_{m}\right)}
\end{gathered}
$$

Where $\mathrm{N}$ is the number of data point, $\mathrm{y}_{\mathrm{p}} \mathrm{i}$, is the network prediction, $\mathrm{y}_{\exp } \mathrm{i}$, is the experimental response, $y_{m}$ is the average of the experimental value and $i$ is an index of data.

\section{Results and discussion}

\subsection{Optimization of the ANN structure and genetic algorithm optimization}

The Matlab R2011a genetic algorithm Toolbox has been used to forecast the photocatalytic degradation over $\mathrm{TiO}_{2}$ of an aqueous solution containing the Oxytetracycline antibiotic (OTC). The optimal architecture of the ANN model was selected by considering the maximum value of $\mathrm{R}^{2}$ and the lowest value of the MSE of the testing set [28]. Too few neurons causes under-fitting and too many neurons in hidden layer leads to over fitting the model by raising the complexity of the model [24,29]. Plotting the MSE versus number of neuron in hidden layer confirm that construction of the model with 1-24 of neurons in the hidden layer permit the accuracy and repeatable prediction of experimental data (Fig. 3). Table 1 shows the relation between the number of neurons, $\mathrm{R}^{2}$ and MSE for selected ANN. The application of 18 hidden neurons permits to obtain the best values for $\mathrm{R}^{2}$ and MSE; 0.99751 and $7.504 \mathrm{e}-04$, respectively. It indicates that the training was good and the network 
can be used for final prediction of photocatalytic degradation of OTC with suspended $\mathrm{TiO}_{2}$. Increasing the neurons number from 18 to 24 lead to increase (0.0007504 to 0.0033$)$ the MSE, while the $\mathrm{R}^{2}$ decreased from 0.99757 to 0.9866 . The exhibition of MSE versus the number of epochs for optimal ANN model (Fig. 4) shows that the training was stopped after 43 epochs. The results for the fitting in different stages such as training, validation test and all data are presented in Fig. 5 with optimum number of processing elements in the hidden layer. It can be seen that the ANN model makes accurate predictions in the training and testing stages. Therefore, the ANN model is capable of simulating and predicting the photocatalysis degradation of OTC with $\mathrm{TiO}_{2}$ in suspension. The fitness function for ANN model that correlates the inputs with output can be defined as follows:

$A N N_{\text {output }}=$ Purelin $(w 2 * \log \operatorname{sig}(w 1 *[x(1) ; x(2) ; x(3) ; x(4)]+b 1)+b 2)$

Where $x(1), x(2)$ and $x(3)$ represent the inputs; $w 1$ and $b 1$ are the weight and bias of hidden layer, respectively; and w2 and b2 are the weight and bias of output layers, respectively. These parameters are listed in Table 2.

\subsection{Relative importance of input variables}

The relative importance of the influence of each input variable on the output variable can be obtained through the neural weights matrix [30]. The ANN used in this work provided the internodes weights (table 2). These weights are analogous to synapse strengths between the axons and dendrites in real biological neurons. For each input variable, the percentage change in the output, as a result of the change in the input variable, was calculated via the following equation.

$I_{j}=\frac{\sum_{m=1}^{m=N h}\left(\left(\left|W_{j m}^{i h}\right| / \sum_{k=1}^{N i}\left|W_{k m}^{i h}\right|\right) \times\left|W_{m n}^{h 0}\right|\right)}{\sum_{k=1}^{k=N_{i}}\left\{\sum_{m=1}^{m=N} h\left(\left|W_{k m}^{i h}\right| / \sum_{k=1}^{N i}\left|W_{k m}^{i h}\right|\right) \times\left|W_{m n}^{h 0}\right|\right\}}$

where $I_{j}$ is the relative importance of the $j t h$ input variable on output variable, $N_{i}$ and $N_{h}$ are the number of input and hidden-neurons, respectively, $W s$ are connection weights, the 
superscripts $i, h$ and $o$ refer to input, hidden and output layers, respectively, and subscripts $k$, $m$ and $n$ refer to input, hidden and output neurons, respectively [30,31].

Table 3 shows the relative importance of various variables calculated by equation 13 . As table 3 indicates, all of the variables (initial concentrations of OTC, amount of catalyst, initial $\mathrm{pH}$ value and irradiation time) have strong effects on OTC degradation efficiency. The irradiation time and amount of catalyst are the most influential parameters in the degradation process of OTC with relative importance of 52.94 and $21.45 \%$, respectively, followed by initial concentrations of OTC and initial $\mathrm{pH}$ value with a relative importance of $13.424 \%$ and 12.186, respectively. Therefore, none of the variables studied in this work could have been neglected from the present analysis.

\subsection{Preliminary experiments}

Fig. 6 shows the elimination of OTC with an initial concentration of $20 \mathrm{mg} / \mathrm{L}$ in various systems: under UV irradiation and without catalyst (photolysis), in the dark with $\mathrm{TiO}_{2}$ (adsorption) and under UV irradiation in the presence of $\mathrm{TiO}_{2}$ (photocatalysis). The results obtained show that a low degradation of OTC was observed during the direct photolysis, where less than $12 \%$ OTC was reduced within 180 minutes of irradiation. With $\mathrm{TiO}_{2}$ alone, only $21 \%$ of the initial concentration of OTC was sorbed during the first 60 minutes under agitation. However, in the presence of $\mathrm{TiO}_{2}$ with UV light, $86.13 \%$ of OTC was removed. Hence, the better degradation of OTC was observed when the solution was illuminated by UV coupled with the catalysts, confirming that the generation of ${ }^{\bullet} \mathrm{OH}$ was significantly more efficient under $\mathrm{UV} / \mathrm{TiO}_{2}$ than under UV alone.

\subsection{Influence of the initial OTC concentration}

The effect of the OTC's initial concentration on the photocatalytic degradation was studied by varying the concentration of OTC in the range 5-20 mg/L with a constant $\mathrm{TiO}_{2}$ concentration of $1 \mathrm{~g} / \mathrm{L}$ and a $\mathrm{pH}$ value of 7.3. Reactions were carried out at room temperature. The results 
are shown in Fig. 7. As can be seen, experimental and predicted values by artificial neural network were almost the same. Experimental data obtained from kinetic studies were fitted to a first-order (Eq.12). The apparent rate constants ( $\left.k_{\text {app }}\right)$ were determined by plotting the natural logarithm of the ratio between initial concentration and the concentration of OTC after t minutes of UV irradiation against irradiation time and the kinetic parameters are listed in Table 4. As seen from the data presented in Table 4, the initial concentration had a significant impact on the apparent rate constant $\left(\mathrm{k}_{\mathrm{app}}\right)$ and the initial degradation rate $\left(\mathrm{r}_{0}\right)$, since the former decreased and the latter increased for increasing initial OTC concentration 0.216 to $0.089 \mathrm{~min}^{-1}$ and from 1.08 to 1.79 for 5 to $20 \mathrm{mg} / \mathrm{L}$ initial OTC amount, respectively. In addition, the degradation yield decreased with the increase of the OTC's initial concentration. Indeed, it was completely degraded within 30 and 70 minutes of UV irradiation at 5 and 10 $\mathrm{mg} / \mathrm{L}$ initial concentration, respectively; while and even after 180 minutes final degradation yields were only 94.88 and $86.13 \%$ a 15 and $20 \mathrm{mg} / \mathrm{L}$ initial concentration, respectively (Fig.7 and Table 4). This can be explained by the fact that for higher initial concentrations, more substrates occupies a greater number of $\mathrm{TiO}_{2}$ active sites reducing the generation of the oxidants ${ }^{\bullet} \mathrm{OH}$ (Eqs. (2) and (3)) leading to lower degradation yields [32]. On the other hand, a higher OTC concentration absorbs more photons, decreasing consequently the available photons to activate $\mathrm{TiO}_{2}$ and a deficiency of photons to activate $\mathrm{TiO}_{2}$ surface delays the degradation of OTC. In conclusion, the initial concentration of OTC and the surface reaction with ${ }^{\circ} \mathrm{OH}$ radical are the limiting factors during the degradation of OTC under $\mathrm{UV} / \mathrm{TiO}_{2}$ system, which mainly occurs on the surface of $\mathrm{TiO}_{2}$. Therefore, the optimal concentration was found to be $10 \mathrm{mg} / \mathrm{L}$, and after 180 minutes, the negligible residual OTC suggests that OTC molecules were merely degraded into more stable intermediary byproducts [33]. The kinetic parameters are determined by the following equations:

$\ln \left(\mathrm{C}_{0} / \mathrm{C}\right)=k_{\text {app }} \cdot t$ 
$r_{0}=k_{a p p} \cdot C_{0}$

$t_{1 / 2}=\ln (2) / k_{a p p}$

Where $\mathrm{C}_{0}$ and $\mathrm{C}$ are the concentrations of OTC $(\mathrm{mg} / \mathrm{L})$ at the initial time $\mathrm{t}_{0}$ and a given time, respectively. $r_{0}$ is the initial degradation rate $(\mathrm{mg} / \mathrm{L} . \mathrm{min})$ and $\mathrm{t}_{1 / 2}$ is the half-life time of reaction (min), namely the time at which half of the initial amount of OTC disappears.

\subsection{Optimization of the photocatalyst amount}

In order to get the optimum catalysts loading, to have a maximum of absorbance of incident photons, a series of experiments were carried out with $\mathrm{TiO}_{2}$ concentrations ranging from 0.125 to $2 \mathrm{~g} / \mathrm{L}$ and were compared with a predicted value by artificial neural network. As seen in Fig. 8, it seems that using such a low concentration of $\mathrm{TiO}_{2}(0.125 \mathrm{mg} / \mathrm{L})$ was inadequate for an effective treatment of OTC. The degradation yields after 180 minutes irradiation increased from 69.2 to $86.7 \%$ for $\mathrm{TiO}_{2}$ amounts increasing from 0.125 to $1.0 \mathrm{~g} / \mathrm{L}$, respectively (table 5). It can be noted that the yields of photocatalytic degradation of OTC increased significantly with increasing $\mathrm{TiO}_{2}$ concentration in the range $0.125-1.0 \mathrm{~g} / \mathrm{L}$. This may probably be due to the increase in the number of surface active sites, available for the photocatalytic reaction and enhanced generation of hydroxyl radicals due to the increase of the concentration of charge carriers [32,34]. However, a further increase of $\mathrm{TiO}_{2}$ concentration above $1.0 \mathrm{~g} / \mathrm{L}$ did not produce significant enhancement in OTC degradation. This result can be attributed to the high degree of scattering by the catalyst particles, a decrease in light penetration and an increase in the opacity [35,36], as well as to the loss in surface area occasioned by agglomeration at high loading prevents the absorption of photons by the catalyst [37]. According to these results, the optimal $\mathrm{TiO}_{2}$ concentration for OTC degradation in aqueous solutions appears to be $1.0 \mathrm{~g} / \mathrm{L}$. This concentration was therefore considered thereafter. 


\subsection{Effect of the initial $\mathrm{pH}$ value}

The $\mathrm{pH}$ is considered as one of the major factors affecting the behavior and the fate of OTC in the environment [38]. $20 \mathrm{mg} / \mathrm{L}$ of OTC was considered and the initial $\mathrm{pH}$ values examined were in the range 1.3 to 9.3 respectively, which was adjusted by adding dilute solution of $\mathrm{NaOH}$ or $\mathrm{HCl}$. The results, summarized in Fig.9 and table 6, show that after 180 minutes of irradiation the degradation yield was optimal at neutral $\mathrm{pH}$, namely for $\mathrm{pH} 7.3$ (87.54\%). This can be explained by taking into consideration the properties of both the antibiotics and the catalyst related to the $\mathrm{pH}$. The $\mathrm{pH}$ at which the surface of an oxide is uncharged is defined as the Zero Point Charge $\left(\mathrm{pH}_{\mathrm{zpc}}\right)$, which is about $6.0 \pm 0.7$ for $\mathrm{TiO}_{2}$ [39] and hence $\mathrm{TiO}_{2}$ is positively charged below $\mathrm{pH}=6.7$ and negatively charged above $\mathrm{pH}=6.7$ according to [40]:

$\mathrm{TiOH}_{2}^{+} \longleftrightarrow \mathrm{TiOH}+\mathrm{H}^{+}$

$\mathrm{TiOH}+\mathrm{OH}^{-} \longleftrightarrow \mathrm{TiO}^{-}+\mathrm{H}_{2} \mathrm{O}$

Therefore, at a $\mathrm{pH}$ value of 7.3 , the electrostatic attraction between the negatively charged $\mathrm{TiO}_{2}$ surface and OTC distributed in major part in its zwitterion $\left(\mathrm{H}_{2} \mathrm{OTC}{ }^{ \pm}\right)$form and small amount in monoanionic (HOTC-) form [41] is favored, explaining potentially the higher degradation yields at near-neutral conditions. On the other hand, in acidic solution $(\mathrm{pH}=1.3)$, $\mathrm{TiO}_{2}$ and OTC $\left(\mathrm{H}_{3} \mathrm{OTC}^{+}\right)$are positively charged and in alkaline solution $(\mathrm{pH}=9.3), \mathrm{TiO}_{2}$ is negatively charged while the negatively charged $\mathrm{OTC}^{2-}$ is also present at this $\mathrm{pH}$. So, at both $\mathrm{pH}$ values (1.3 and 9.3), repulsive forces between the catalyst and the antibiotic occurred, delaying the adsorption of OTC on the catalyst surface and hence leading to low degradation yields. 


\section{Conclusion}

The above results confirmed that the degradation was faster at low concentrations and that the irradiation time needed for total degradation decreased with the initial concentration. The initial $\mathrm{pH}$ of the solution had an important effect on the degradation performances, which were related to the different electric charge state of OTC species.OTC degradation yield decreased with the increase of the acidity or alkalinity. In addition, the developed repulsive forces between the $\mathrm{TiO}_{2}$ catalyst and the antibiotic delayed OTC adsorption $\mathrm{TiO}_{2}$ surface. The higher yield was obtained close to neutral conditions $(\mathrm{pH}=7.3)$. There was a synergistic effect between photolysis and adsorption on $\mathrm{TiO}_{2}$ which led to an increase of the degradation yield. The results show also that the mass of the catalyst was limited by an optimal value $(1.0 \mathrm{~g} / \mathrm{L})$, beyond which no improvement on the rate of degradation can be reported. OTC degradation yields was successfully predicted by using a three layer ANN with a log sigmoid transfer function 'logsig' at hidden layer, and a linear transfer function 'purelin' at output layer. Finally, 18 neurons in the hidden layer allowed to obtain the best values for $\mathrm{R}^{2}$ and MSE; 0.99751 and 7.504e-04 respectively. 


\section{References}

[1] Rigos, G.; Nengas, I.; Alexis, M.; Troisi, G.M. Aquat Toxicol 2004, 69, 281-288.

[2] Lai, H.-T.; Chien, Y.-H.; Lin, J.-S. Aquaculture 2008, 275, 96-101.

[3] Hassani, A.; Khataee, A.; Karaca, S. J Mol Catal A Chem 2015, 409, 149-161.

[4] Fukahori, S.; Fujiwara, T. J Environ Manag 2015, 157, 103-110.

[5] Antonopoulou, M.; Konstantinou, L. Clean- Soil Air water 2013, 41, 593-600.

[6] Halling-Sørensen, B.; Nielsen, S.N.; Lanzky, P.F.; Ingerslev, F.; Lützhøft, H.C.H.; Jørgensen, S.E. Chemosphere 1998, 36, 357-393.

[7] Sarmah, A.K.; Meyer, M.T.; Boxall, A.B.A. Chemosphere 2006, 65, 725-759.

[8] Rozas, O.; Contreras, D.; Mondaca, M.A.; Pérez-Moya, M.; Mansilla, H.D. J Hazard Mater 2010, 177, 1025-1030.

[9] Lu, C.; Mai, F.; Wu, C.; Wu, R.; Chen, C. Dyes Pigment 2008, 76, 706-713.

[10] Malato, S.; Blanco, J.; Vidal, A.; Richter, C. Appl Catal B-Environ 2002, 37, 1-15.

[11] Gaya, U. I.; Abdullah, A.H.; J Photochem Photobiol C-Photochem Rev 2008, 9, 1-12.

[12] Fujishima, A.; Zhang, X.T. C R Chim 2006, 9, 750-760.

[13] Agustina, T.E.; Ang, H.M.; Vareek, V.K. J Photochem Photobiol C-Photochem Rev 2005, 6, 264-273.

[14] Liu, B.; Wen, L.; Zhao, X. Mater Chem Phys 2008, 112, 35-40.

[15] Malato, S.; Fernández-Ibáñez, P.; Maldonado, M.I.; Blanco, J.; Gernjak, W. Catal Today 2009, 147, 1-59.

[16] Witmann, G.; Demeestere, K.; Dombi, A.; Dewulf, J.; Langenhove, H.V. Appl Catal B-Environ 2005, 61, 47-57.

[17] Çelekli, A.; Geyik, F. Bioresour Technol 2011, 102, 5634-5638.

[18] Prakash, S.N.; Manikandan, A.; Govindarajan, L.; Vijayagopal, V. J Hazard Mater 2008, 152, 1268-1275.

[19] Sabonian, M.; Behnajady, M.A. Desalination and Water Treatment 10.1080/19443994.2014.963161.

[20] Eskandarloo, H.; Badiei, A.; Behnajady, M.A.; Afshar, M. Res Chem Intermed 10.1007/s11164-015-2000-y.

[21] Behnajady, M.A.; Eskandarloo, H. Res Chem Intermed 10.1007/s11164-013-1327-5.

[22] Eskandarloo, H.; Badiei, A.; Behnajady, M.A. Ind Eng Chem Res 2014, 53, 68816895. 
[23] Ghanbary, F.; Modirshahla, N.; Khosravi, M.; Behnajady, M. A. J Environ Sci 2012, 24(4), 750-756.

[24] Kiranşan, A.M.; Khataee, L.; Karaca, S.; Sheydaei, M. Spectrochimica Acta Part A: Molecular and Biomolecular Spectroscopy 2015,140, 465-473.

[25] Qiang, Z.; Adams, C. Water Res 2004, 38, 2874-2890.

[26] Elemen, S.; Kumbasar, E.P.A.; Yapar, S. Dyes Pigment 2012, 95, 102-111.

[27] Despagne, F.; Massart, D.L. Chemom Intell Lab Syst 1998, 40, 145-163.

[28] Yetilmezsoy, K.; Demirel, S. J Hazard Mater 2008, 153, 1288-1300.

[29] Karsoliya, S. Int J Eng Trend Technol 2012, 3, 714-717.

[30] Garson, G.D. AI Expert 1991, 6, 47-51.

[31] Kasiri, M.B.; Aleboyeh, H.; Aleboyeh, A. Environ Sci Technol 2008, 42, 7970-7975.

[32] Yang, L.; Yu, L.E.; Ray, M.B. Water Res 2008, 42, 3480-3488.

[33] Shaojun, J.; Shourong, Z.; Daqiang, Y.; Lianhong, W.; Liangyan, C. J Environ Sci 2008, 20, 806-813.

[34] Yang, H.; Li, G.; An, T.; Gao, Y.; Fu, J. Catal Today 2010, 153, 200-207.

[35] Khalid, N.R.; Ahmed, E.; Hong, Z.; Zhang, Y.; Ullah, M.; Ahmed, M. Ceram Int 2013, 39, 3569-3575.

[36] Liu, H.; Dong, X.; Duan, C.; Su, X.; Zhu, Z. Ceram Int 2013, 39, 8789-8795.

[37] Muthirulann, P.; Devi, C.N.; Sundaram, M.M. Ceram Int 2014, 40, 5945-5957.

[39] Zhao, C.; Pelaez, M.; Duan, X.; Deng, H.; O'Shea, K.; Fatta-Kassinos, D.; Dionysiou, D.D. Appl Catal B-Environ 2013, 134-135, 83-92.

[39] Ohtani, B. J Photochem Photobiol C-Photochem Rev 2010, 11, 157-178.

[40] Konstantinou, K.I.; Albanis, T.A. Appl Catal B-Environ 2004, 49, 1-14.

[41] Park, H.-R.; Kim, T.H.; Bark, K.-M. Eur J Med Chem 2002, 37, 443-460. 
Table 1. Comparison of 24 neurons in the hidden layer for removal efficiency by the ANN model development with the Levenberg-Marquardt algorithm for OTC.

\begin{tabular}{cllcccccc}
\hline $\begin{array}{l}\text { Number of } \\
\text { neurons }\end{array}$ & $\mathrm{R}^{2}$ & MSE & $\begin{array}{l}\text { Number of } \\
\text { neurons }\end{array}$ & $\mathrm{R}^{2}$ & MSE & $\begin{array}{l}\text { Number of } \\
\text { neurons }\end{array}$ & $\mathrm{R}^{2}$ & $\mathrm{MSE}$ \\
\hline 1 & 0.7272 & 0.0315 & 9 & 0.9806 & 0.0036 & 17 & 0.9891 & 0.0016 \\
2 & 0.9121 & 0.0093 & 10 & 0.9841 & 0.0035 & 18 & 0.99757 & $7.504 \mathrm{e}-04$ \\
3 & 0.9480 & 0.0074 & 11 & 0.9792 & 0.0032 & 19 & 0.9584 & 0.0035 \\
4 & 0.9650 & 0.0043 & 12 & 0.9884 & 0.0026 & 20 & 0.9901 & 0.0025 \\
5 & 0.9594 & 0.0056 & 13 & 0.9868 & 0.0013 & 21 & 0.9825 & 0.0017 \\
6 & 0.9821 & 0.0030 & 14 & 0.9860 & 0.0026 & 22 & 0.9805 & 0.0031 \\
7 & 0.9688 & 0.0042 & 15 & 0.9902 & 0.0021 & 23 & 0.9790 & 0.0032 \\
8 & 0.9645 & 0.0023 & 16 & 0.9877 & 0.0025 & 24 & 0.9866 & 0.0033 \\
\hline
\end{tabular}

Table 2. The weight and bias of trained ANN for predicting the photocatalysis degradation of OTC with $\mathrm{TiO}_{2}$ in suspension.

\begin{tabular}{|c|c|c|c|c|c|c|}
\hline \multicolumn{4}{|c|}{ w1 } & \multirow{2}{*}{ w2 } & \multirow{2}{*}{ b1 } & \multirow{2}{*}{$\mathrm{b} 2$} \\
\hline$x(1)$ & $x(2)$ & $\mathrm{x}(3)$ & $x(4)$ & & & \\
\hline-9.1623 & -4.4703 & 0.0389 & 6.6506 & -2.7141 & -12.261 & \multirow{18}{*}{8.3944} \\
\hline 2.6629 & -5.618 & 0.966 & 1.0483 & -2.0155 & -4.7853 & \\
\hline 2.2725 & -3.5879 & -1.0199 & -3.2354 & 0.4406 & -5.9591 & \\
\hline 2.9705 & 0.3565 & -3.8294 & -2.0867 & 1.3457 & -0.6024 & \\
\hline 3.9241 & -3.3822 & -0.5971 & 1.4636 & 2.0595 & -3.2177 & \\
\hline-3.6324 & 4.0706 & 0.0252 & -1.8476 & 2.2241 & 2.2693 & \\
\hline-0.0124 & 0.9307 & 14.2795 & -0.0875 & -8.0901 & 14.309 & \\
\hline-0.1843 & 4.3144 & 5.2989 & 6.3068 & -3.3051 & 1.2609 & \\
\hline 0.2918 & -5.8279 & -9.9219 & 0.9280 & -2.2085 & -3.3124 & \\
\hline-0.4099 & 4.5858 & 3.4056 & 6.4729 & 3.5941 & 0.8083 & \\
\hline-0.4137 & -2.8091 & 3.4247 & -1.5025 & -0.5647 & 1.2692 & \\
\hline-1.1672 & -4.3848 & 2.105 & 2.596 & 3.5142 & -5.0405 & \\
\hline 1.9256 & 0.5828 & -3.6491 & -2.3463 & -2.0332 & -0.1841 & \\
\hline-7.7105 & -0.1419 & -0.5099 & -0.9629 & 0.7735 & -5.5992 & \\
\hline 3.7739 & 1.1939 & 3.7909 & 0.8962 & 0.3586 & 6.3907 & \\
\hline 6.2795 & 3.9198 & -3.978 & 4.1991 & -2.1664 & 7.8506 & \\
\hline 1.5687 & -2.6576 & 2.1884 & 5.2203 & -1.2519 & 4.557 & \\
\hline-25.7053 & -0.41855 & -0.1217 & 0.5015 & 16.6521 & -27.96 & \\
\hline
\end{tabular}


Table 3. Relative importance of the input variables in the percentage of OTC degradation.

\begin{tabular}{ll}
\hline Input variable & Relative importance (\%) \\
\hline Initial concentration of OTC & 13.424 \\
Amount of catalyst & 21.450 \\
Irradiation time & 52.940 \\
Initial pH value & 12.186 \\
\hline
\end{tabular}

Table 4. Kinetic parameters determined after three hours of UV irradiation of OTC at various initial concentrations for $1 \mathrm{~g} / \mathrm{L} \mathrm{TiO}_{2}$ and a $\mathrm{pH}$ value of 7.3.

\begin{tabular}{lllll}
\hline $\begin{array}{l}\mathrm{C}_{0} \\
(\mathrm{mg} / \mathrm{L})\end{array}$ & $\begin{array}{l}\mathrm{k}_{\mathrm{app}} \\
(/ \mathrm{min})\end{array}$ & $\begin{array}{l}\mathrm{r}_{0} \\
(\mathrm{mg} / \mathrm{L} \cdot \mathrm{min})\end{array}$ & $\begin{array}{l}\mathrm{t}_{1 / 2} \\
(\mathrm{~min})\end{array}$ & Degradation yield \% \\
\hline 5 & 0.216 & 1.082 & 3.20 & 100 \\
10 & 0.127 & 1.268 & 5.46 & 99.64 \\
15 & 0.103 & 1.529 & 6.71 & 94.88 \\
20 & 0.089 & 1.791 & 11.84 & 86.13 \\
\hline
\end{tabular}

Table 5. First order kinetic constants, half-lives and degradation efficiency for the degradation of $20 \mathrm{mg} / \mathrm{L}$ of OTC under different concentrations of $\mathrm{TiO}_{2}$ by $\mathrm{UV} / \mathrm{TiO}_{2}$ system.

\begin{tabular}{lllll}
\hline $\begin{array}{l}{\left[\mathrm{TiO}_{2}\right]} \\
(\mathrm{mg} / \mathrm{L})\end{array}$ & $\begin{array}{l}\mathrm{k}_{\text {app }} \\
\left(\mathrm{min}^{-1}\right)\end{array}$ & $\begin{array}{l}\mathrm{t}_{1 / 2} \\
(\mathrm{~min})\end{array}$ & $\mathrm{R}^{2}$ & $\begin{array}{l}\text { degradation efficiency \% } \\
(180 \mathrm{~min})\end{array}$ \\
\hline 0.125 & 0.0089 & 77.88 & 0.98 & 69.20 \\
0.25 & 0.0131 & 52,91 & 0.97 & 80.29 \\
0.50 & 0.0218 & 31,79 & 0.97 & 82.45 \\
1.00 & 0.0273 & 25,39 & 0.98 & 86.67 \\
1.50 & 0.0261 & 26.55 & 0.95 & 85.79 \\
2.00 & 0.0245 & 28.29 & 0.97 & 84.20 \\
\hline
\end{tabular}


Table 6. First order kinetic constants, half-lives and degradation efficiency for the degradation of $20 \mathrm{mg} / \mathrm{L}$ of OTC at different initial $\mathrm{pH}$ values by $\mathrm{UV} / \mathrm{TiO}_{2}$ system.

\begin{tabular}{lllll}
\hline $\mathrm{pH}$ & $\begin{array}{l}\mathrm{k}_{\text {app }} \\
\left(\mathrm{min}^{-1}\right)\end{array}$ & $\begin{array}{l}\mathrm{t}_{1 / 2} \\
(\mathrm{~min})\end{array}$ & $\mathrm{R}^{2}$ & $\begin{array}{l}\text { degradation efficiency \% } \\
(180 \mathrm{~min})\end{array}$ \\
\hline 1.30 & 0.0223 & 31.08 & 0.983 & 75.17 \\
3.27 & 0.0191 & 36.29 & 0.992 & 84.87 \\
7.30 & 0.0293 & 23.65 & 0.981 & 87.54 \\
9.30 & 0.0232 & 29.87 & 0.993 & 77.66 \\
\hline
\end{tabular}




\section{Figure legends}

Fig. 1. Chemical structure of oxytetracycline.

Fig. 2. Schematic diagram of the three layers ANN model with four input and one output layer used in this study.

Fig. 3. Effect of the number of neurons in the hidden layer on the performance of the neural network.

Fig. 4. MSE versus the number of epochs.

Fig. 5. Experimental values vs Predicted values of normalized degradation from the ANN model in training, validation, test and all data.

Fig. 6. OTC removal by $\mathrm{UV}, \mathrm{TiO}_{2}$ and $\mathrm{UV} / \mathrm{TiO}_{2}$ with $1 \mathrm{~g} / \mathrm{L} \mathrm{TiO}{ }_{2}$ concentration, $[\mathrm{OTC}]_{0}=20$ $\mathrm{mg} / \mathrm{L}$ and a $\mathrm{pH}$ value of 7.3.

Fig. 7. Photocatalytic degradation of OTC under UV light at different initial OTC concentrations and comparison with predicted ANN output results at $1 \mathrm{~g} / \mathrm{L} \mathrm{TiO} 2$ and a $\mathrm{pH}$ value of 7.3 .

Fig. 8. Effect of the $\mathrm{TiO}_{2}$ dose on the degradation of OTC under UV irradiation with $20 \mathrm{mg} / \mathrm{L}$ of OTC and a $\mathrm{pH}$ value of 7.3; and comparison between experimental and ANN output results.

Fig. 9. Effect of the initial $\mathrm{pH}$ values on the photocatalytic degradation of OTC for an initial concentration of $20 \mathrm{mg} / \mathrm{L}$ and $1 \mathrm{~g} / \mathrm{L}$ of $\mathrm{TiO}_{2}$; and comparison between experimental and ANN output results. 